\title{
SPACES OF BELONGING AND THE PRECARIOUSNESS OF HOME
}

\author{
ERIK BORMANIS \\ Stony Brook University
}

On May 20, 2018, the New York Times published "Unsheltered," an article series detailing the ways that New York City landlords abuse the housing court system, one of the busiest courts in the United States with 69,000 cases a year, in order to evict tenants from the apartments they called home (Barker et al. 2018). Capitalizing on the highly profitable housing market in New York City, after evicting the previous occupants, the landlords then renovate these apartments and charge hugely inflated rents to higher-earning tenants. The previous occupants are at best forced to leave their present neighborhoods for another, to leave for another state, or at worst, are made homeless. Such actions, sometimes carried out blocks at a time on behalf of large corporations like the Orbach Group, Thor Equities, or any number of multi-million dollar corporations, consequently carry out the large-scale uprooting of not only specific individuals, but often entire communities that had once called those neighborhoods home.

Such stories of precarious housing, as most of us are likely aware, are not limited to the highly lucrative real estate market of New York City, nor even to low-income tenants, though they have been and continue to be the most vulnerable. In 2016, across the United States, there were 2.3 million evictions filed, no doubt in part because the median asking rent between 1995 and today has increased by seventy percent, adjusted for inflation (Gross 2018). Similarly, the rates of home-ownership have sharply declined for millennials across the West: The Guardian, for example, reports that in the UK half as many millennials (twenty-five- to thirty-four-yearolds) compared to baby boomers will own their own house by age thirty (Savage 2018), and the Huffington Post reports that home-ownership in Canada is at an all-time low due to rapidly increasing housing prices coupled with relatively stagnant wage growth (Tencer 2017). Personal ownership of one's housing, it seems, is becoming a luxury and not a necessity, and is becoming an increasingly unlikely one for those who do not have the means to afford down-payments or finance mortgages on increasingly inflated property prices. Such precariousness, I plan to demonstrate here, is precipitated and even made possible by a certain tacit (though sometimes overt) understanding of what housing is, specifically, the notion that housing is not a fundamental condition of human life related to our being "at home" in the world, but a commodity to be bought and sold on the free market, "real estate" or, as is increasingly common, a major financial "investment." "This latter understanding of housing as investment is certainly at play

\footnotetext{
${ }^{1}$ This understanding, in particular, being the one that led to the subprime mortgage crisis of 2007-2008, which essentially treated individual home-ownership as a secondary concern to capital accumulation, insofar as the banks, and not the homeowners, were given massive bail-outs. It also denotes just how fundamental the value of real-estate is to our contemporary economy.
} 
for real estate corporations, but is also operative at the level of many middle-class home owners who treat their property as their biggest financial asset, which they can use as collateral for their children's student loans or sell to fund their eventual retirement. It is my contention here that this understanding of housing as commodity and investment is complicit in creating a world where fewer and fewer people have adequate housing in the very concrete sense of having a shelter that will guarantee a minimal level of stability for the foreseeable future; furthermore, that the lack of such housing and the way its distribution is organized forecloses the more general possibility of feeling situated or "feeling at home" in the world at all.

Whether or not we want to entertain his conclusions in the face of such facts, I believe Heidegger's critical question during the post-WWII housing crisis in Germany - "what is the state of dwelling in our precarious age?" - remains timely $(2001,158)$. This question has certainly sparked debate within academic circles of philosophy, but has unfortunately not yet become a fundamental question at either the level of everyday conversation or public policy. For Heidegger, the impetus for his reflections was the shortage of housing after much of the housing stock was destroyed after the war, but for us, there is no such housing shortage. Indeed, in both the United States and Europe, the number of vacant houses largely outnumbers the number of homeless individuals, indicating the absurd situation where a vacant house is more desirable, for the company or individual who owns it, than one occupied by the wrong people or for the wrong price.

To be at home is to be situated, to know one's surroundings and what to expect, whereas one's "housing" is an individual (or intimate/familial) space which filters and orients one's engagements with the world. When housing is precarious, we might call it a mere "shelter," a temporary space in which you can rest, but which is essentially temporary. The Odyssey, interestingly enough, demonstrates all three modes of inhabitation: from "home," Ithaca itself where Odysseus' family and wealth are, to Calypso's island which afforded comfort and stability, but not "home," to the hole Odysseus covers with leaves on the island of Phaeacia, which offers only a minimal shelter from the elements after he washes up on shore. It is therefore my goal here to consider the experience of being at home with a critical consideration of such issues of precarious housing and to demonstrate, drawing upon and moving beyond the reflections of Gaston Bachelard and Martin Heidegger, how what is at stake in such situations of precarious housing might be a more radical problem than a failure of distributive justice.

I will argue that such precariousness, suffered by specific individuals, communities, or younger generations, denotes a more general foreclosure of the very possibility of feeling at home in the world. To this effect, I will consider various descriptions of loss of housing and feeling out of place or unwelcome, together with a careful analysis of the phenomenological descriptions of dwelling and home. I will claim there are at least two interconnected but distinct aspects of feeling at home: first, the continuity or stability offered by permanent housing, and second, of our being situated (and therefore situating the occupant) in a wider social context and "feeling at home" within it. In the contemporary world, the possibilities of both permanent housing and the durable sense of home it enables are increasingly being occluded by an understanding of housing as an increasingly lucrative commodity and capital asset. 
I.

\section{SOLITUDE, CONTINUITY, AND THE FAILURES OF THE WELFARE STATE}

We begin to address how issues of shelter and the moral and existential stakes of these issues are thrown into relief by first considering the task that Bachelard in The Poetics of Space (1994) sets himself. He writes:

I must show that the house is one of the greatest powers of integration for the thoughts, memories, and dreams of mankind ... In the life of man, the house thrusts aside contingencies, its councils of continuity are unceasing. Without it, man would be a dispersed being. It maintains him through the storms of the heavens and through those of life. (6-7)

Bachelard understands this to be a challenge to Henri Bergson's metaphysics of time, where time is essentially duration [durée], the continuous and indeterminate flow of time that, if described as a specific moment or instant, would no longer constitute "duration," but rather a frozen image of time; that is, the geometrical tracing of the movement of a hand through space, rather than the hand in motion, which never occupies its entire trajectory at a given time. This is crucially important to note because Bachelard's approach, which he calls "topoanalysis," rests upon the claim that "[t]he finest specimens of fossilized duration concretized as a result of long sojourn, are to be found in and through space" (9). Such moments of fossilized time matter, but they matter only on the condition of having a space in which they can take shape. Our memories need spaces to "hook on to," and even if we have since left them, these places often come back to us through dreams or when we move through similar spaces. ${ }^{2}$ If time requires space to fossilize, then our having a place in the house becomes a crucial phenomenon that contributes to the depth and fullness of human life.

Further elaborating on this point, Bachelard then claims that to form indelible memories we require solitude and solitude is always achieved in specific places: corners, garret rooms, crawlspaces, and attics. These are the places that children have moments to themselves, are able to cultivate a personality, coiling in upon themselves like a shell, and discover their own interiority. ${ }^{3}$ To be sure, there is good reason to argue that solitude is never sufficient for a sense of complete subjectivity or interiority, as so many authors make clear, but Bachelard is nevertheless correct in saying that "all the spaces of our past moments of solitude, the spaces in which we have suffered from solitude, enjoyed, desired and compromised solitude, remain indelible within us, and precisely because the human being wants them to remain so" (1994,

\footnotetext{
${ }^{2}$ There are two further places we might look to support this thesis: in Deleuze \& Guattari's What is Philosophy? they discuss the idea of art as a "monument" of compressed time (1994, 167). Janet Donohoe, in Remembering Places: A Phenomenological Study of the Relationship Between Memory and Place (2014), studies at length the way that spaces ground not only memory, but also a sense of connectedness to culture and tradition.

${ }^{3}$ Emmanuel Levinas, too, uses this imagery of "coiling" to describe subjectivity and its relationship to its environment in Totality and Infinity (1969, 118).
} 
10). ${ }^{4}$ Bachelard understands this psychoanalytically: the spaces of the attic, the crawlspace, etc., all form powerful affective images that shape us, and thereby accrue specific affective valences. No matter what later might come to pass, we will always have been the child who retreated to that attic, who daydreamed in the quiet spaces of the home. We carry our intimate spaces of childhood with us through such indelible images, and because they are indelible, such images assist in giving us a sense of continuity: they anchor us to the world. For the purposes of this paper, we should further emphasize how moments of solitude, of retreating into a familiar and comfortable space, is also a way to gather our energy, to rest. Thus, those who are not afforded the possibility of having such spaces are at the same time not afforded the possibility of solitude, and on Bachelard's account, would not as easily be able to form the indelible images that ground us in the world and maintain us through the world's variability and challenges. To use Bachelard's own vocabulary, instability in our dwelling spaces risks making a human being a "dispersed being," although he quickly passes over this possibility of dispersion as essentially secondary insofar as all being is immediately well being. It is, he writes, "already a value. Life begins well, it begins enclosed, protected, all warm in the bosom of the house" (7). Unfortunately, from the outset our homes can be places of violence, uncertainty, and contestation, often in ways we might even overlook (as we will see in our treatment of the administration of welfare below). Bachelard's metaphysical reorientation from Heidegger, in other words, overlooks precisely the "thrownness" and contingency involved in the relative stability or instability of one's childhood home, and in so doing, overlooks the contingent and political factors that must be interrogated in any account of dwelling.

We ought to expand Bachelard's point here by saying that the home is more than just an anchor for our memories and a sense of depth or subjectivity, but also serves as a pre-condition for a full participation in democratic political life. Kirsten Jacobson, in her article, "The Experience of Home and the Space of Citizenship" (2010), makes precisely this point, arguing that our existence as civic individuals is made possible by the intimate, interpersonal anchor of the home. Therefore, Jacobson argues, entertaining the liberal idea that we are all isolated individuals is only possible if we take for granted the intersubjective undergirding that fosters the growth of such isolatable individuals. If a liberal society ignores this precondition, Jacobson argues, it risks "the possibility for gross mistreatment of the very citizens it is attempting to describe and cultivate" (245).

I can think of no more revealing example of such mistreatment (though there are certainly more sinister or devastating ones) than the way welfare is administered in the United States. Welfare, at least ostensibly, is meant to guarantee the basic conditions its citizens require to live in a given society, which often (rightly) include providing access to affordable or subsidized housing. In Fustice and the Politics of Difference (1990), however, Iris Marion Young argues that while welfare might be a good thing, and it might be an important step to guarantee such basic conditions, it nevertheless exercises a form of oppression. There are two crucial flaws in the welfare system on her account: first, it deprives those dependent upon it of certain rights and freedoms that others possess, and secondly, it blocks forms of respect and a feeling of social usefulness (itself a precondition of feeling at home, but one which lies beyond the scope of this paper) due to the stigma attached to receiving welfare benefits. In support of the first claim, she writes:

${ }^{4}$ In Totality and Infinity (1969), for example, Levinas' goal is to show the ultimate insufficiency of the coiling-in of subjectivity upon itself. Similarly, Maurice Merleau-Ponty consistently emphasizes throughout his work how the individual is always imbricated within an "anonymous," "general," and "pre-personal" world of intersubjectivity. Interestingly, Bachelard himself claims that it is through returning to the images of home through sleep that "we may perhaps experience a type of repose that is pre-human; pre-human, in this case, approaching the immemorial" $(1994,10)$. 
In meeting needs of the marginalized, often with the aid of social scientific disciplines, welfare agencies also construct the needs themselves. Medical and social service professionals know what is good for those they serve, and the marginals [sic] and dependents themselves do not have the right to claim to know what is good for them. (54)

Due to the highly bureaucratized nature of how welfare benefits are administered, the recipients of such benefits must often subject themselves to authorities with which most of us do not have to concern ourselves. Such authorities place limits on what kinds of food can be purchased with food stamps, or require that the beneficiaries of welfare constantly prove that they are at the same time employed or actively looking for further employment. Even more pointedly, the beneficiaries of public housing are often subjected to stringent security measures. In City of Quartz (1990), for example, Mike Davis describes the Imperial Courts Housing Project in Los Angeles, which "has . . . been fortified with fencing, obligatory identity passes and a substation of the LAPD," and where "[v]isitors are stopped and frisked, while the police routinely order residents back into their apartments at night" (244). To accept welfare, therefore, means to abdicate our decision-making powers in specific areas of our life, even as it guarantees that we can meet our material needs.

In such a situation, the demands of a rational bureaucracy begin to intrude on the intimate space of the home. This consequence of the structure of welfare benefits transgresses the affective qualities of home that both Bachelard and Jacobson reveal to us: if it is only on the basis of the intimate continuity and stability of the home that we can then participate fully in the world, then the constant bureaucratic demands of the welfare state undermine the continuity required by what it aims to guarantee. We may house those who are lucky enough to receive welfare benefits (after negotiating the paperwork requirements), but do we therefore guarantee them a home? Bachelard implicitly illustrates the difficulty here when he writes: "How often have I wished for the attic of my boredom when the complications of life made me lose the very germ of all freedom!" (1994, 16-7). Often stretched thin by an increasingly demanding pace of life, we seek comfort in familiar spaces, but the way welfare is administered makes the human space of retreat and solitude one of the most pressing and complicated affairs in an already complicated life as it makes the intimate space that is supposed to protect and enable us to struggle in the world yet another place of struggle. There is therefore a fundamental discontinuity built into the structure of welfare provisions for housing, which undermines the continuity required for such housing to be a full "home" in a Bachelardian sense.

As human beings, we need moments of solitude and retreat, we require a private space to call our own; we need a space where, even if the walls are porous, even if we can hear the neighbors fighting or the traffic on the street, we feel as if we can relax and forget the concerns of the outside world. The human being is "a being who does not want to melt away, and who, even in the past, when [s] he sets out in search of things past, wants time to 'suspend' its flight" $(1994,8)$. Without such a basic structure in which to house ourselves, without our nooks and corners, we are at the mercy of time, caught up wholly in the "duration" of our immediate needs and actions, and we lack a place to gather ourselves before setting out into the world, as citizens, as workers, or even as fully formed subjects. 


\title{
II.
}

\section{THE SITUATEDNESS OF HOME: DWELLING}

We ought to admit, however, the limitations of Bachelard's analysis. For Bachelard, the paradigmatic home seems to be a rural French house, to the point where he claims that city living pales in comparison insofar as it lacks both verticality and cosmicity, a relationship between the house and its natural surroundings. In fact, Bachelard is generally unaware of the specificity of his own idiosyncratic experience of home, claiming, for example:

From my viewpoint, from the phenomenologist's viewpoint, the conscious metaphysics that starts from the moment when the being is 'cast into the world' is a secondary metaphysics. It passes over the preliminaries, when being is being-well, when the human being is deposited in a being-well, in the well-being originally associated with being. $(1994,7)$

Substituting "my" with "the phenomenologist's" viewpoint is an all too common slight of hand in the phenomenological tradition. Indeed, Bachelard's hostility towards the idea that human experience involves any measure of being "cast into the world" indicates a discomfort, on his part, with the variability that can occur in our situations of home: our homes can be precarious, or even places of downright hostility. Bachelard, as comfortably housed, suggests that on an ontological level, the most primordial being is well-being. Speaking from a very different worldly position, namely, as a Chicana lesbian, Gloria Anzaldúa, in Borderlands/La Frontera (1987) provides a starkly different description of the world:

\begin{abstract}
The world is not a safe place to live in. We shiver in separate cells in enclosed cities, shoulders hunched, barely keeping the panic below the surface of the skin, daily drinking shock along with our morning coffee, fearing the torches being set to our buildings, the attacks in the streets. Shutting down. Woman does not feel safe when her own culture, and white culture, are critical of her; when the males of all races hunt her as prey. (20)
\end{abstract}

Indeed, Anzaldúa goes on to mention a heterosexual student who believed that homophobia meant fear of going home, which prompts Anzaldúa to think to herself, "how apt. Fear of going home. And of not being taken in. We're afraid of being abandoned by the mother, the culture, la Raza, for being unacceptable, faulty, damaged" (20). If we are attempting to describe phenomenologically the experience of being a human, we absolutely must include a description of being-at-home, and Bachelard contributes greatly to this discussion. That being said, Anzaldúa points us towards the necessity of being critical of our descriptions of such experiences insofar as they might overlook the determinate historical or political conditions that make this or that experience possible, in this case, insofar as we must make our homes within a cultural milieu that makes them more or less sheltering, more or less homely. For Bachelard, it might very well have been the case that the home was a good home, and that it perfectly served him as place to cultivate the habits and memories that undergird his fuller participation in the world. Not everyone, however, would write that in the experience of home, "[i]t is as though in this material paradise, the human being were bathed in nourishment, as though $[\mathrm{s}]$ he were gratified with all the essential benefits" (1994, 7). In Anzaldúa's example, the systematic targeting of women of 
color and identifiable queer people in society at large never quite dissipates, even in the intimacy of home. Even if such forces were not motivated enough to destroy the home itself, facing violence and harassment on the street can be enough to make even a well-built house with a loving family take on the valence of a prison. All human beings need solitude, they need spaces to dream in, to be sheltered in, but we are not like the hermit crab: we do not carry our homes on our back, we do not always carry with us the possibility for solitude and retreat, but rather, our homes are situated in neighborhoods, in cities, in nations, in cultures.

Thus far, we have focused primarily on the lack or precarity of "shelter," but Anzaldúa's unromantic and precarious description of home points us to the necessity of interrogating the way the physical space of the shelter is situated within a wider social context. Despite her radically different perspective than Heidegger, they would seem to be in agreement upon this point, as "Building, Dwelling, Thinking" begins with a consideration of how feeling at home (which he calls "dwelling") cannot simply be reduced to a mere shelter. Heidegger brings up the example of saying "[t]he truck driver is at home on the highway, but he does not have his shelter there; the working woman is at home in the spinning mill, but does not have her dwelling place there; the chief engineer is at home in the power station, but he does not dwell there" (2001, 143-4). Such people feel at home in these places because they have the habits and practices that correspond to them, they feel in sync with such places. These examples are, however, gendered, which brings us to the further consideration that certain groups of people are capable or incapable of feeling at home in certain structures, contexts, or situations. Shannon Sullivan, in Revealing Whiteness (2006) for example, claims that one of the important phenomenological aspects of being white is what she calls "ontological expansiveness," the implicit assumption that all spaces are or could be inhabited (10). A white person, in other words, could in principle imagine themselves being at home anywhere, whereas a non-white person might be limited in the spaces they can occupy, and might feel that limitation even in imagining possible places they might want to feel at home. That being said, Heidegger's goal here is to say that building a road, a spinning mill, or a power station would also be indicative of what he calls "dwelling," insofar as "building is not merely a means and a way toward dwelling - to build is in itself already to dwell" (2001, 144, italics added). We build, we might say, because we dwell, and dwell in the sense of "a staying with things" (149). If we substitute our previous use of "feeling at home" with "dwelling," we gain the crucially important temporal dimension to our inhabitation of the home: to be at home means to dwell there, to stay for the foreseeable future.

We dwell insofar as we are the beings that are capable of seizing time and of clearing a space for things to be seen, whether those things be monuments, infrastructure, or a house. A bridge, to use Heidegger's example, shows us the earth, the sky, and the comings and goings of the people who use it; the bridge reveals a "place" to which we human beings are somehow attuned. Such an example, however, must lead us to ask the further critical question as to who gets to cross this bridge, or perhaps, who resides under it, as a minimal shelter from the elements, while others pass above. Our buildings might all generate spaces, might all indicate an essential and primordial "dwelling" of our being upon the earth, but such spaces are determinate, and as such, are differentially experienced by different people. The new shopping plaza might become a space for young professionals to spend money at shops catered to their tastes, but for those who were evicted from their homes for its construction, for the business owners who once catered to a community that has been displaced, its boutique shopping might announce only the harsh absence of what once was reflected in the space in which they no longer belong. ${ }^{5}$

${ }^{5}$ I am thinking here of the story of Brooklyn's Fulton Mall discussed at some length in The Brooklyn Wars by Neil deMause (2016, 213-270). 
I am interrogating Heidegger here not so much to advance his thesis in "Building, Dwelling, Thinking," but rather as a starting point to indicate the ways in which housing or shelter is caught up in a wider context of what we might call "dwelling" or "belonging." To be sure, part of what it means to have shelter is that, even if the walls of our given shelters are porous, letting the elements and the comings and goings of other people in, they mark out a space that is our own, they allow something special to happen, which allows us a crucial distance from other people and the elements. As Heidegger teaches us, however, this is caught up in a wider context: dwelling opens up onto a world we "inhabit," forming the habitual modes of interaction that make us feel at home in a space, and from this anchoring space of belonging, we can then venture out into the world. Such spaces form the nexus of our "orientation" towards the world by supplying a "here" to get to "there." Moreover, Heidegger's focus on spaces that are not simply dwelling spaces seems to me to be crucial: the structures beyond the home through which we move, which we share with the people who share our world, which form part of our "neighborhood," so to speak, are just as much implicated in our sense of belonging. Imagine, for example, if suddenly the bridge we take to work were closed, if our neighbors were forced out of our neighborhood and replaced with strangers: such moments, though not specifically targeting our own specific dwelling or "house," nevertheless threaten our sense of dwelling. We are thrown back onto our situation instead of fully inhabiting it.

While Heidegger stresses dwelling as a fundamental fact about humans, namely, that to be human is to dwell, given our previous considerations about the precariousness of housing, we should be wary of taking this to mean that all human beings always feel as if they belong in the world. Heidegger himself mentions those who have experienced a "loss of rapport with things that occurs in states of depression," which "would be wholly impossible if even such a state were not still what it is as a human state: that is, a staying with things" (155, italics in original). Feeling a loss of rapport with the world, in other words, is still a mode of being with the world: only the kind of being that expects or feels as if they ought to belong can feel its lack. ${ }^{7}$ But depression is not the only form of losing such a rapport, and indeed, it is becoming more and more clear that the political organization of who gets to dwell merits attention. We should not, in other words, treat dwelling as if it were simply a fact about being human, but as something that requires, to use Heidegger's own terminology, "work," albeit the explicitly political kind of work that Heidegger is so reticent to mention. Indeed, a large part of the "crisis" of dwelling that Heidegger diagnoses is itself the result of Germany's instigation of the Second World War, which resulted in the destruction of many of the cities in Germany and their venerable housing stock by allied bombing. Heidegger's ignorance of this fact, and his treatment of "dwelling" as a primarily metaphysical problem, demonstrate precisely how any proper understanding of dwelling must contend with its historical and political conditions. ${ }^{8}$

Throughout "Building, Dwelling, Thinking," Heidegger repeatedly tries to reverse the seemingly obvious priority between building and dwelling. We do not first build a shelter, and then dwell within it, but it is precisely because we are the kinds of beings that dwell that we build anything at all. But this primordial sense of dwelling in the context of contending with a housing crisis goes too far. It presumes, as Sullivan's concept of "ontological expansiveness" describes, a subject who could potentially occupy all spaces (or indeed, one who already does): whose "belonging" is a necessary consequence or property of their being at all, "for when I

\footnotetext{
${ }^{6}$ For more on orientation, and specifically how it relates to sexual orientation and others, see Sara Ahmed's Queer Phenomenology (2006). Indeed, much of my emphasis on the limitations of the phenomenological descriptions of Bachelard and Heidegger is inspired by her approach to Husserl in this text.

${ }^{7}$ See the work of Matthew Ratcliffe on how this characterizes the phenomenon of depression, particularly, "The Interpersonal Structure of Depression" (2018).

${ }^{8}$ For more on this point, see W.G. Sebald's On the Natural History of Destruction (1999).
} 
say 'a man' I already name the stay within the fourfold among things" (2006, 154). But it is increasingly clear that we, as a society, are not building for everyone as rates of declining home ownership, the increasing development of temporary housing (often in the form of luxury condominiums), and rising numbers of evictions all attest. Our housing crisis is worse than the one Heidegger discusses. He is comforted, at least, by the fact that good houses are being built in post-war Germany, even if they do not guarantee that dwelling occurs in them. For us, however, building, in the form of real-estate development, and dwelling with its aspect of belonging in a place for the foreseeable future, are fundamentally opposed, insofar as development always requires more development in service of the generation of capital.

A particularly troubling example of such incompatibility, and indeed, of the "gross mistreatment" of which Jacobson (2010) warns, is given in the second of the New York Times article series, "The Eviction Machine Churning Through New York City" (Barker et al. 2018). In the article, the authors detail the story of Neri Carranza, who had lived in the same apartment on West 109th street since 1956. In 2010, she was facing eviction after the Orbach Group had paid seventy-six million for her building and most of the nearby block. As a rent-regulated tenant, Ms. Carranza could not be evicted without cause, but the Orbach group hired a lawyer to evict her for a supposed breach of lease. In Ms. Carranza's case, they alleged that she had been using her $\$ 300$ a month rent-regulated apartment as a storage space, while she lived with a friend nearby. She denied this and the courts ruled in her favor. ${ }^{9}$ Having tried the legal means, the Orbach group resorted to extra-legal means: when Ms. Carranza later asked for repairs in 2014, the company claimed she needed to leave for them to complete the repairs, which she did, and in 2016 the repairs had still not been completed. After years of fighting, and a total of nineteen court dates, Ms. Carranza decided to settle her case for $\$ 100,000$, turned over her uninhabitable apartment to the company, and is now living with her niece in Carlisle, Pennsylvania. At the time the article was published, her apartment had been renovated and was being rented for $\$ 3,500$ a month by two Columbia University students.

This is a clear case of injustice, and indicates the extra-legal means that large corporations have at their disposal to evict their tenants and maximize their investment in the lucrative housing market. For some, $\$ 100,000$ (though well below what the apartment is worth) and the prospect of moving to another place might be perfectly acceptable. Ms. Carranza's reaction to this settlement, however, points us to the heart of the present issue: Ms. Carranza was at home in her Spanish-speaking neighborhood, whereas in Carlisle, Pennsylvania "there is no church with service in Spanish. No grocery catering to Latinos. No old friends to visit. There are not even any sidewalks" (Barker et al. 2018). Feeling at home, dwelling means having a place to serve as an anchor of continuity throughout one's life, and moreover, a place that is situated in such a way that the world around it feels welcoming, familiar, and inviting. The cynical point of view that might say $\$ 100,000$ is a suitable replacement for the roots she had laid down in her neighborhood, or even that the injustice here was that the apartment was worth more than what she was offered, miss the point completely. To be at home is a fundamental condition of human life, and in Ms. Carranza's case, her apartment and the life that came with it were viewed as secondary considerations (or more plausibly, did not even enter consideration) to maximizing the returns on a seventy-six million dollar investment. We might, in many ways, carry our habits with us, and in so doing, also carry our home with us. Indeed, Anzaldúa, despite her profound apprehension in the face of a hostile world, nevertheless claims, "in leaving home I did not lose touch with my origins because lo mexicano is in my system. I am a turtle, wherever I go I carry 'home' on my back" $(1987,21)$. We inhabit the world based on our habits,

\footnotetext{
${ }^{9}$ This tactic is colloquially referred to as a "fishing expedition." Once the corporation decides a tenant should be evicted, the corporation's lawyers then search for any breach of lease that can be feasibly argued.
} 
but these habits, if we are denied a place of our own, if we can no longer lay down our roots with any sense of security, can serve as limitations in a new context, as Ms. Carranza's did in her forced move to Pennsylvania, and indeed, as so many economic migrants experience when they are forced to leave their country due to the global inequality of wealth and opportunity.

Despite his overly sentimental and limited perspective on the problem of dwelling, Heidegger does point us in a valuable direction: for we should ask what understanding of home is operative in these domains where home is made impossible, precarious, or alienating for certain people. Heidegger claims that " $[\mathrm{t}]$ he real dwelling plight lies in this, that mortals ever search anew for the nature of dwelling, that they must ever learn to dwell," and to transform the "dwelling plight" we must first seek out the ways in which we misunderstand dwelling so as to destroy it or make it impossible (2001, 159, italics in original). This is our crisis today, as more and more people are being dispossessed or denied the opportunity to dwell, as more and more forms of dwelling dissipate in the continuous and rapid world of development for development's sake. The extent of such a crisis should provide all the more opportunity for even those of us who have relatively stable housing situations, relatively stable places in our society, to reconsider our own place in a world that becomes less human by the day.

\section{III.}

\section{THE PAST, THE FUTURE, AND “HOW MUCH” HOME WE NEED}

Let us now note the qualities that define feeling at home that we have described so far: the first, is a sense of security and continuity, which implies a relatively stable future; the second related point is that such security and continuity extend beyond the scope of the home or shelter itself, into both our politics and culture. To concretize these attributes, we turn now to Heidegger's ideal dwelling and the structures of past and future that characterize it. He describes a house in the Black Forest, its structure designed and situated to weather the elements gracefully, but for our purposes, we should note that:

... it made room in its chamber for the hallowed places of childbed and the 'tree of the dead' - for that is what they call a coffin there: the Totenbaum - and in this way it designed for the different generations under one roof the character of their journey through time. $(2001,158)$

A house that clears space for dwelling is one that makes room for our journey through time: not temporarily, but continuously, from past to future. Another way to say this might be: the house is not subject to some general or abstract time, but itself mediates and makes possible certain experiences of time. Heidegger understands this in a very thick generational sense, as the house of our ancestors and our future children. But we do not need to go so far: we need only remember how Ms. Carannza, residing in her apartment for half a century, had a past there, had laid down roots in the community, who missed seeing her old friends and attending her church. We also need to remember that her future there was cut short: that dwelling place, unbeknownst to her, did not house her future, but rather, the future of those who, in paying 11.6 times more rent than her, were seen as more worthy tenants. The increasing lack of home ownership and the increasingly precarious status of housing, then, at the same time, undermine the possibility 
of a human future, insofar as our homes are increasingly subject to the rapid and unforeseen fluctuations of the market and society at large.

How, then, does the past play in to the experience of dwelling if it need not be generational? In the New York Times article, Ms. Carranza revisits her unrecognizable renovated apartment and finds her past there, the sedimented memories and sense of ownership destroyed as if they had never happened. Jean Améry, a survivor of the holocaust, describes a similar experience undergone by many Jewish people when the Nazi party relocated them from their homes and communities. In At the Mind's Limits (1980), he reflects on what he and other German Jews lost when the Nazi party declared the Jewish people to be no longer "German." As Améry notes, many merchants and artisans lost not only their goods, money, and home, but also their status as professionals, losing their role in their communities. Such an event not only deprives them of a future as professionals, but also importantly robs them of the past as they are no longer seen as a part of the "community" in which they had a place. Even more revealing is the example of Alfred Mombert, a German-Jewish Neo-Romantic poet who was forcibly relocated to an internment camp. Mombert writes to his friend that he had lost everything, that it all flowed off of him (indicative of an experience of temporality where things fail to cohere), and that it was so unthinkable that such should happen to a "German poet." Here lies the sad contradiction for Améry. Mombert did not recognize that he was no longer a German poet, because

... only someone who writes poetry not merely in German but also for Germans, upon their express wish, can be a German poet; that when everything flows off, the last traces of the past will also be swept along. The hand that was not raised in his protection cast the old man out. (60)

In the case of the mass forced deportation of German Jews, we can see how this works: the past, which had sedimented into their identities, was taken from them and forever erased, their place in society and the meaning of all their past actions permanently lost. Indeed, in the case of Berlin in the Third Reich, imperial boulevards and grand buildings meant to signal Germany's glory were to be built over old Jewish neighborhoods, much as luxury condos are popping up today in previously underserved neighborhoods in American cities. ${ }^{10}$ If a group of Germans had fought for them, perhaps, there would be some sliver of belonging left, some sense that their past as Germans meant something. Sadly, this was not the case for Alfred Mombert and many others like him. Happily, the New York Times article detailing so many tenants' struggles constitutes some recognition that they have a place, but we must ask ourselves if this is enough to safeguard some small part of the dwelling of the millions threatened with eviction and loss of home, and all the more so when it is precisely our forms of life, as academics, intellectuals, and students (the immense privilege of Columbia University students serving a notable role in Ms. Carranza's case) that make it profitable to displace such people.

In 1966, when he originally finished the original German text of At the Mind's Limits, Améry notes that the destruction of worlds of value might very well make possible a new cosmopolitanism, that, in having the specificity of their homeland taken from them, the Jewish people

${ }^{10}$ See Albert Speer, Inside the Third Reich (1970). In particular, Chapter 5, "Architectural Megalomania" (50-70). 
might have gained the world. This is not at all convincing or comforting to him. He worries that in uprooting a people from their home, which lends a value to things, a change will take place:

The objects of daily use, which at present we still imbue with emotion, will be fully fungible. Already, American city planners are thinking of turning the house into a consumable commodity in the future. One hears that at intervals of twenty to twenty-five years entire sections of the city will be demolished and rebuilt, since house repairs will be as little worthwhile as certain auto repairs already are. $(1980,56)$

Améry's worries here show us two things: first, that Améry, writing in Europe in 1966, believes this is a phenomenon on the horizon. In other words, the idea that housing is ultimately a replaceable commodity is a relatively new idea in the history of the world. The house, which should be a space for values to inhere, which should be (on our analysis, here) a space for time, is made a victim of time, made essentially temporary. If such a world comes to pass, Améry asks: "how would one still be able to form the concept of home at all?" (56). If it is not already, then our world is quickly advancing in this direction. Can we still form this concept? With the help of a careful phenomenological analysis, I believe we can, and even though Heidegger and Bachelard, established European intellectuals writing in the 1950's, do not seem to grasp the true precariousness of housing, they are right to emphasize its importance in rendering our worlds cohesive, stable, and in lending them a sense of continuity. Unfortunately, forming the concept is not enough because home requires actual spaces, it requires activities of building, and indeed, it also requires us to raise our hands in the protection of others whose houses and homes are at stake.

If both our enmeshment in the past and our continuity into the future are at risk, if we no longer have the space to form memories, or a space that is our own to give some shape to our future, then we are living in a world where we treat human beings more and more, to cite Mombert, as if "everything flows off," or to use Bachelard's phrasing, as if we were "dispersed" beings, as if we had no spatial or temporal thickness to us, as if our lives, along with the intimate and public places we live them out were mere commodities, capable of being tossed aside like "old food cans," or worse yet, as less than commodities, as the mere potential for capital investment (Adorno 2005, 67). And if we do not raise our hand in protection for those who are dispossessed now, whose ways of life, solitude, and daydreams are counted for nothing, we give too much over to an understanding of home that treats it as an impermanent commodity, or even worse, one of many ticking numbers in the rapid flow of investment capital.

In spite of this, we might say that things are hopeful: for even when it occurs minimally, even in spite of everything, dwelling can and does occur. We might certainly eke out an existence in precarious positions, and indeed, may even find a home there. The refugee (or, increasingly, detainee) might decorate their tent or temporary room to their taste, and others might make spaces for dwelling in homes known to be temporary. As Améry's somewhat puzzling question, "How much home does a person need?" teaches us, this is because "home" is something of which we can get more or less; it is never "complete" or "finished." I find myself agreeing with Améry that, in the face of home becoming more and more precarious, the answer to that question is that we need much home, indeed, as much as we can get. But what determines who gets 
more or less home? And how do we build more together? I contend here that the first step in such an enterprise is to recognize what is at stake when we talk of housing and home, and to be honest about the fragility and contested nature of dwelling implicit and explicit in our forms of social, economic, and political organization. And if we agree with Améry's uncomplicated and earnest conclusion, that "it is not good to have no home," we must build ourselves and others a different future, or rather, we must take the preliminary step of making space for the future to happen in the intimate spaces of belonging we call "home."

\section{REFERENCES}

Adorno, Theodor. 2005. Minima Moralia: Reflections on a Damaged Life. Translated by E.F.N. Jephcott. New York: Verso.

Ahmed, Sara. 2006. Queer Phenomenology: Orientations, Objects, Others. Durham: Duke University Press.

Améry, Jean. 1980. At the Mind's Limits: Contemplations by a Surivivor on Auschwitz and Its Realities. Translated by Sidney Rosenfeld and Stella P. Rosenfeld. Bloomington: Indiana University Press.

Anzaldúa, Gloria. 1987. Borderlands / La Frontera: The New Mestiza. San Francisco: Aunt Lute Books.

Bachelard, Gaston. 1994. The Poetics of Space: The Classic Look at How We Experience Intimate Places. Translated by Maria Jolas. Boston: Beacon Press.

Barker, Kim, Jessica Silver-Greenburg, Grace Ashford, and Sarah Cohen. 2018. "Unsheltered: The Eviction Machine Churning Through New York City." New York Times, May 20, 2018. https://www.nytimes.com/interactive/2018/05/20/nyregion/nyc-affordablehousing.html

Davis, Mike. 1990. City of Quartz: Excavating the Future in Los Angeles. New York: Verso.

deMause, Neil. 2016. The Brooklyn Wars: The Stories Behind the Remaking of New York's Most Celebrated Borough. Brooklyn: Second System Press.

Deleuze, Gilles and Felix Guattari. 1994. What is Philosophy? Translated by Hugh Tomlinson and Graham Burchell. New York: Columbia University Press.

Donohoe, Janet. 2014. Remembering Places: A Phenomenological Study of the Relationship Between Memory and Place. Lanaham: Lexington Books.

Heidegger, Martin. 2001. Poetry, Language, Thought. Translated by Albert Hofstadter. New York: Harper Perennial Modern Classics.

Gross, Terry. 2018. "First-Ever Eviction Database Shows: 'We're in the Middle of a Housing Crisis." National Public Radio, April 12, 2018. Accessed September 1st, 2018. https://www.npr.org/2018/04/12/601783346/first-ever-evictions-database-shows-werein-the-middle-of-a-housing-crisis

Jacobson, Kirsten. 2010. "The Experience of Home and the Space of Citizenship." The Southern Fournal of Philosophy 48.3: 219-245. 
Levinas, Emmanuel. 1969. Totality and Infinity: An Essay on Exteriority. Translated by Alphonso Lingis. Pittsburgh: Duquesne University Press.

Merleau-Ponty, Maurice. 2012. Phenomenology of Perception. Translated by Donald A. Landes. New York: Routledge.

Ratcliffe, Matthew. 2018. "The Interpersonal Structure of Depression." Psychoanalytic Psychotherapy 32.2: 122-139.

Savage, Michael. 2018. "Millennial Housing Crisis Engulfs Britain." The Guardian, April 28, 2018. Accessed September 1st, 2018. https://www.theguardian.com/society/2018/ apr/28/proportion-home-owners-halves-millennials

Sebald, W.G. 1999. On the Natural History of Destruction. Translated by Anthea Bell. New York: Random House.

Speer, Albert. 1970. Inside the Third Reich: Memoirs. Translated by Richard and Clara Winston. New York: Simon \& Schuster Paperbacks.

Sullivan, Shannon. 2006. Revealing Whiteness: The Unconscious Habits of Racial Privilege. Bloomington: Indiana University Press.

Tencer, Daniel. 2017. "Canada's Millennials Getting Shut Out of Homeownership." Huffington Post, February 28. Accessed September 1, 2018. https:/ /www.huffingtonpost. ca/2017/02/28/millennial-home-ownership-canada-hsbc_n_15062750.html

Young, Iris Marion. 1990. Justice and the Politics of Difference. Camden: Princeton University Press. 